ITP

35,6

1782

Received 1 May 2021

Revised 17 August 2021 30 October 2021

Accepted 17 November 2021

\section{Uncovering the affective affordances of videoconference technologies}

\author{
Simeon Vidolov \\ University College Dublin, Dublin, Ireland
}

\begin{abstract}
Purpose - The purpose of this study is to examine the role of videoconferencing technologies for mediating and transforming emotional experiences in virtual context.

Design/methodology/approach - Drawing on empirical data of video conferencing experiences, this study identifies different constitutive relations with technology through which actors cope with actual or potential anxieties in virtual meetings. It draws on the phenomenological-existential tradition (Sartre and MerleauPonty) and on an interpretive phenomenological analysis (IPA) to conceptualize and illustrate the role of affective affordances in virtual settings.

Findings - The study identifies four different body-technology-other relations that provide different action possibilities, both disclosing and concealing, for navigating emotional experiences in virtual encounters of mutual gazing. These findings offer insights into the anatomy of virtual emotions and provide explanations on the nature of Zoom fatigue (interactive exhaustion) and heightened feelings of self-consciousness resulting from video conferencing interactions.

Originality/value - This paper builds on and extends current scholarship on technological affordances, as well as emotions, to suggest that technologies also afford different tactics for navigating emotional experiences. Thus, this paper proposes the notion of affective affordance that can expand current information system (IS) and organization studies (OS) scholarship in important ways. The focus is on videoconference technologies and meetings that have received little research attention and even less so from a perspective on emotions. Importantly, the paper offers nuanced insights that can advance current research discourse on the relationships between technology, human body and emotions.
\end{abstract}

Keywords Affective affordance, Emotions, Mutual gaze, Body-technology relations, Virtual encounters Paper type Research paper

\section{Introduction}

Communication between geographically distributed teams, enabled by information and communication technologies (ICTs), is commonly referred to as ICT-mediated or "virtual" (Robey et al., 2003; Schultze and Orlikowski, 2001). ICT-mediated communication has become ubiquitous during the Covid-19 pandemic, partly afforded by the availability of various videoconferencing technologies and the heightened number of remotely located employees. For instance, during Covid-19 pandemic, Microsoft Teams reached 75 million daily active users (Zaveri, 2020), whereas the number of Zoom users increased in a period of three months from 10 million to just over 300 million daily meeting participants, and Google Meet surpassed 100 million daily meeting participants (Warren, 2020).

(C) Simeon Vidolov. Published by Emerald Publishing Limited. This article is published under the Creative Commons Attribution (CC BY 4.0) licence. Anyone may reproduce, distribute, translate and create derivative works of this article (for both commercial and non-commercial purposes), subject to full attribution to the original publication and authors. The full terms of this licence may be seen at http:// creativecommons.org/licences/by/4.0/legalcode

The author would like to thank the guest editors and three anonymous reviewers for the insightful comments and suggestions. The author would also like to thank Professor Stefan Klein for the support and feedback on earlier versions of the paper.

Funding: This work was supported by the European Research Council (ERC), grant agreement No 771217.
Information Technology \& People Vol. 35 No. 6,2022 pp. $1782-1803$ Emerald Publishing Limited 0959-3845

DOI 10.1108/ITP-04-2021-0329 
The increase in videoconferencing has also given rise to the emergence of new virtual forms of expressing solidarity and compassion with others located near or far. Various virtual social practices emerged in an attempt to replace the need for face-to-face for socializing and helpgiving. For instance, one popular story was that of a liquor-brand owner, who put out a call on Twitter for people to join him for a virtual cocktail hour [1]. Other attempts to stretch the idea of virtual socializing included virtual weddings and virtual board games trying to replicate the authentic experience of being together with others. On the one hand, videoconferencing tools, such as Zoom, Skype, Teams, etc., have become the means for overcoming the physical separation, being praised for closely replicating face-to-face experiences; on the other hand, there have been reports for interactive exhaustion that became known as Zoom fatigue (Bailenson, 2021) and heightened feeling of self-consciousness, suggesting that this mode of communication significantly diverges from face-to-face experiences [2].

These insights echo a long-standing discussion in information system (IS) that ICTs should not be understood in deterministic terms (Carlson and Zmud, 1999; Markus, 1994; Ngwenyama and Lee, 1997), suggesting instead that the outcomes of communication and collaboration depend on how the technologies are being used, promoting the argument that both the technologies and human users co-constitute each other in this process (Beane and Orlikowski, 2015; Introna and Hayes, 2011). Such a view has also led to the understanding that virtual collaboration is a distinct mode of engagement, compared to face-to-face interactions, and should be understood in its own right (Baralou and Tsoukas, 2015; Hafermalz and Riemer, 2020; Malhotra and Majchrzak, 2014; Schultze and Brooks, 2019). In this context, the concept of affordance has often been drawn on to argue that technologies are formative of different action possibilities and can be enacted differently through different socio-technical practices (Leonardi and Vaast, 2017). For instance, some studies discuss technological affordances that lead to the emergence of new collaborative practices enabling the simultaneous participation in multiple dialogues (Baralou and Tsoukas, 2015), or constructing situational awareness in virtual context (Malhotra and Majchrzak, 2014). Recent research has also pointed out that videoconferencing technologies afford new ways for visual engagements that transform meetings and encounters characterized by mutual gazing (Karl et al., 2021; Regenbrecht and Langlotz, 2015).

These studies have advanced our understanding of virtual collaboration focusing on how they can transform purposeful and task-related activities, but have offered fewer insights into the more fundamental emotional and embodied dimensions of working and relating. For instance, research often portrays virtual interactions, albeit understood in non-deterministic terms, as disembodied and emotionless (e.g. Baralou and Tsoukas, 2015). Empirical evidence from research on videoconferencing technologies, however, often reports the presence of stress, anxiety and emotional fatigue (Bailenson, 2021; Hacker et al., 2020) implying that virtual meetings are formative of emotional experiences. Studies showing the development of intimate relationships and genuine feelings of love in virtual context also contribute to this evidence (e.g. Buchanan and Whitty, 2013; Walther, 1995).

One credible explanation for the insufficient attention to emotions in virtual context is the lack of conceptually sound understanding of the role of the human body in such settings (Schultze, 2014). The human body often "vanishes" in virtual interactions (Vaast, 2007) leading to claims of disembodiment (e.g. Dreyfus, 2008). Such claims coupled with the understanding that the body is the seat of emotions (Stewart and Schultze, 2019) often lead to portrayals of virtual interactions not only as disembodied but also as emotionless (Springgay, 2005). Recent research, however, has criticized such Cartesian views by disputing the division between the virtual as disembodied and face-to-face as embodied (Schultze, 2014). For instance, it has been reported that offline practices and representations are involved in creating online identities, but also online experiences and practices play an important role in constructing both offline and online identities that are entangled and mutually constituted by technology (Introna, 2007). It has been also pointed out that virtual and co-located
Affective
affordances

1783 
ITP

35,6

1784

expressions and experiences are not just a matter of two separate realms or bodies, either virtual or physical, but are rather inseparably produced by both human and technological agencies (Schultze, 2014). As such, these claims allow recognizing emotional experiences, such as trust, anger, frustration, conflict or feelings of oppression or liberation as inherent to virtual collaboration, leading to the understanding that emotions in virtual context can be studied in their own rights (Fineman et al.,2007). This approach would require an exploration of how different ICTs afford ways for conveying bodily cues leading to distinct emotional expressions and experiences (Gilmore and Warren, 2007; Springgay, 2005). Such studies, however, have been scarce in virtual context and particularly so in videoconferencing meetings (Bailenson, 2021).

In order to understand how emotions emerge, become expressed, shared and suppressed within the context of virtual working (Panteli et al., 2021), this study draws on a combination of phenomenological-existential perspective on emotions (Merleau-Ponty, 1962; Sartre, 2003) and post-phenomenological view on body-technology relations (Ihde, 2002). Such a sensibility views emotions as temporally embodied self-feelings (Denzin, 1984, p. 49) that are enacted through circular interactive and relational processes between self and other and in which technology has a co-constitutive role. I bring together and advance these insights through the notion of "affective affordance," which implies that any social situation or aspect of the (social) environment is affectively coloured instantiating affective action and reaction (Fuchs, 2017). Technology as co-constitutive of social situations similarly afford opportunities to express, amplify or suppress affective experiences or, more broadly, afford one to affect and be affected.

Thus, this study offers a two-fold contribution. First, it contributes to the literature on emotions in virtual settings by highlighting and exploring the action and process tendencies of emotions and their circular movements in the processes of seeing and being seen, emotionally affording and actualizing self and other in virtual working encounters. Second, it expands our understanding of technological affordances beyond actional possibilities for purposeful and goal-oriented activities foregrounding the role of technologies for navigating relational and emotional processes. More specifically, the findings identify and delineate different body-technology relations that uncover different action possibilities, both concealing and disclosing, for managing emotional expressions and experiences through videoconferencing technologies. Thus, this study contributes to recent attempts to understand how technology "rematerializes" relational processes holding implications for furthering our understanding of virtual collaboration (Beane and Orlikowski, 2015; Introna and Hayes, 2011). It also enriches discourses on situated socio-technical action (Suchman, 2007) by foregrounding the importance of the existential situation of the actor indelibly consisting of her affections, feelings and moods (Ciborra, 2002).

\section{Virtuality and emotions: a literature review \\ 2.1 Virtual collaboration and affordance}

The emergence of new modes of ICT-mediated communication has been accompanied by attempts to theorize them based on comparisons with face-to-face communication. The general disposition towards these new forms of communication has been of inferior quality (Dubé and Robey, 2009). In contrast, face-to-face meetings (Maznevski and Chudoba, 2000; Ramesh and Dennis, 2002) have been considered a source of richness (Daft and Lengel, 1986) due to immediacy and range of non-verbal cues of interactions.

This position has been contested by other authors, who have pointed out that in certain situations, teams and their members can develop authentic relationships in virtual settings (Hinds and Kiesler, 2002; Schinoff et al., 2019), suggesting that virtual collaboration is a distinct mode of engagement that should be understood in its own right (Baralou and 
Tsoukas, 2015; Hafermalz and Riemer, 2020; Malhotra and Majchrzak, 2014; Schultze and Brooks, 2019). Such an orientation entails a different conceptualization of the relationship between human and technology, which in stark contrast with the techno-centric claims that attribute the outcome of communication to technical features (Ngwenyama and Lee, 1997).

The perspective on "affordance" (Leonardi and Vaast, 2017) is often drawn upon to understand the outcome of virtual collaboration in terms of sociotechnical practices rather than in terms of the ICT type and its level of reliance (Malhotra and Majchrzak, 2014). More specifically, technologies are considered formative of different action possibilities emerging through the relationship with users. For instance, Dennis et al. (2010) have shown that virtual collaboration reconstitutes "front" and "back" regions of interaction and highlight the emergence of new practices, such as "invisible whispering", that refers to parallel backstage conversations afforded by instant messaging technologies. In a similar vein, Baralou and Tsoukas (2015) show how these affordances allow interlocutors to mobilize more voices in the front region and offer more opportunities for reflexive interactions with artifacts.

The use of videoconferencing technologies have been also recently studied from an affordance perspective. For instance, Hacker et al. (2020) offer an account of the videoconferencing affordances, such as enabling togetherness or facilitating access to shared social activities with family and friends. Similarly, Waizenegger et al. (2020) offer empirical data suggesting that affordances depend on the personal circumstances of users where family people working from home are more likely to find virtual meetings intrusive and blurring work-life boundaries. Another study shows how videoconferencing technologies transform the way interlocutors engage in mutual gazing due to the positional offset between the capturing camera and display, being relevant for the way empathy and trust are developed (Regenbrecht and Langlotz, 2015). Following this line of research, a recent study discusses some of the limitations of videoconferencing vis-à-vis face-to-face meetings. These include the inability to reproduce lifesize presence, to observe what attendees are looking at, to see attendees' body language and gestures, and to have side conversations with one or more participants (Karl et al., 2021). Such distinct features of videoconferencing technologies give rise to different affordances for conducting meetings (Geenen, 2017).

The notion of affordance is developed by Gibson (1986) to show how the environment guides and scaffolds actions and perception in species-specific ways. Thus, affordances are neither properties of the animal alone nor properties of the environment alone. Instead, they are action possibilities formed by the relation between the abilities of an animal and the features of the situation. Applied to IS research, technologies are considered formative of different action possibilities emerging through the relationship with users, involving mutual adapting and leading to emergence of new communicative practices (Leonardi and Vaast, 2017). The studies that draw on the affordance perspective, however, predominantly focus on the "goal-oriented" and functional aspects of interactions (Strong et al., 2014) and neglect the social situation and its relational and emotional dimensions. Ciborra (2002), for instance, criticises inquiries into situated social-technical action that do not consider the emerging situation of the actor constituting her affections, feelings and moods. Fuchs (2017) furthers these insights suggesting the notion of "affective affordance" pointing out that just as a tree might be seen as "climbable", certain situations or encounters with others might appear "important", "worthwhile", "attractive" or "repulsive", reminding us of the fundamental role of emotions in meaningful collaborations.

\subsection{Technology and emotions}

It has been argued that the IS literature often ignores the role of emotions and feelings and devalues their importance for understanding IS use (Thompson, 2012). McGrath (2006) contends that emotions often become subsumed within discussion of the political processes surrounding IS implementation. The majority of research that discusses the role of emotions
Affective
affordances

1785 
ITP

35,6

1786

is focused on IS innovation initiatives (Bala and Bhagwatwar, 2018; Ciborra, 2002; McGrath, 2006; Stein et al., 2015; Wastell, 1996). Such initiatives involve significant organizational changes that prove to be a fertile context for understanding the relationship between emotions and technology-enabled change. For instance, Bala and Bhagwatwar (2018) show how different systems might elicit divergent emotional dispositions - either positive as job security and satisfaction or negative as job anxiety and emotional exhaustion. Stein et al. (2015) offer granular insights into different emotional reactions that an IT innovation can stimulate leading to different adaptation strategies and shaping different use patterns.

Another relevant strand of the IS literature on emotions deals with the phenomenon of technostress that is defined as stress experienced due to multitasking, constant connectivity, information overload, frequent system upgrades and technical problems associated with the organizational use of ICT (Tarafdar et al., 2010). Such problems involve adjustments to constantly evolving ICT and the changing physical, social and cognitive requirements related to ICT use (Maier et al., 2015). Different technostress creators result in strains that can be either psychological or behavioural. The psychological strains are emotional reactions to stressor conditions and include, among others, dissatisfaction with the job, depression and negative self-evaluation, whereas the behavioural strains include reduced productivity, increased turnover, absenteeism and poor task performance (Tarafdar et al., 2010). One common reaction to technostress is techno-exhaustion (Ayyagari et al., 2011) that is very similar to "Zoom fatigue", connected to feelings of physical and mental exhaustion and anxiety, reported in relation to the excessive use of videoconferencing (Bailenson, 2021). Other examples of negative reactions related to videoconferencing use have been the fear of being on camera, exposing one's private space and lacking security (e.g. Zoom bombing) (Hacker et al., 2020).

While some of these emotional experiences might be in the realm of technostress, others have more interactive and relational origin. For instance, some studies that examine distributed and virtual collaborations, beyond purposeful activities, foreground the importance of relational practices that might be emotionally demanding and anxiety provoking (Aarrestad et al., 2015; Tsoukas, 2009; Vidolov et al., 2020). Similarly, studies on online communities examine the role of emotional attachment and commitment as inherent to communal organizing (Bateman et al., 2011; Ren et al., 2007). These studies have also highlighted the importance of attending to emotions and affect for developing better theoretical explanations of collaborative processes. While emotions have been considered inherent to such forms of virtual collaboration, it has also been pointed out that they have to be studied in their own right as distinct occurrences compared to those emerging in co-located settings (Fineman et al., 2007). This means that emotions might not only be triggered and experienced differently in virtual settings but also that different ICTs can afford new ways for conveying bodily cues and enacting novel emotional expressions (Gilmore and Warren, 2007; Springgay, 2005). Yet, we have only scarce understanding as to how emotions emerge, become expressed, shared and suppressed within the context of virtual working (Panteli et al., 2021). Even in the cases when prior research on virtual collaboration has touched on the topic of emotions and how they become enacted through different gestures and cues (Walther et al., 2015; Walther, 1995), the focus primarily has been on linguistic interactions, and little attention has been paid to emotional experiences and expressions in meetings afforded by videoconferencing technologies (Bailenson, 2021).

To address this gap, this paper will draw on a phenomenological-existential sensibility (Denzin, 1984) that is sensitive to the relational and processual aspects of emotions in situations of mutual gazing (Sartre, 2003). Exploring how emotions manifest and shape the process of virtual collaboration can help us develop a more nuanced understanding of this process, as well as uncover aspects that might have remained invisible to more rational theoretical underpinnings (Denzin, 1984, p. 7). Furthermore, a focus on virtual-conference 
meetings characterized by processes of mutual gazing would offer novel insights into the role of visual and bodily cues and how they transform emotional experiences and expressions.

\section{Phenomenological and existential perspective on emotions and technology}

\subsection{Embodied inter-affectivity: affective affording between self and other}

The phenomenological and existential interpretation of emotions moves away from understanding emotions as cognitive responses to psychological, cultural or structural factors (Denzin, 1984). Instead, emotions are seen as interactive processes best studied as social acts involving interactions with self and others. To understand and study emotions, one has to focus on inter-subjective relations or interactive episodes (Denzin, 1984). The phenomenological-existential tradition does not start with the isolated individuals and their respective inner states, but understands sociality as a pre-reflective process of mutual modification of bodily and emotional states (Fuchs, 2017).

3.1.1 The relational body. The human body is not understood as a physical substance, limited to its skin, but as more-than-physical, relational and "othered" (Merleau-Ponty, 1962; Sartre, 2003). The body understood as a process “bodying forth" (Heidegger and Boss, 2001) or movement between self and other (Merleau-Ponty, 1968) comprised two dimensions. These are "body one" or "body-for-me", which points to our lived experience related to movement and sensations, and "body two" or "body-for-other", which resonates with our image of self, designating a conceptual understanding of body and self (Ihde, 2002). The distinction between the lived experience or tactile feeling of one's body and the visual or specular experience of the body is formative of our subjectivity, but also of our intersubjective relationships. Communicative interactions, thus, are not mechanistically bridging separate egos, but are rather enactive processes (Fuchs and de Jaegher, 2009) of accomplishing and performing body-subjects, identities and inter-subjectivities (Weiss, 2008). This means that not only is one's access to her own thoughts is not immediate, and therefore not too different from that of others, but also that one always already requires a concrete or imaginary "other" that serves as the "mirror" for one's body image and self-awareness (Diprose, 2002). Just as thoughts are not authored by an autonomous, rational thinker, but accomplished in dialogue with the "other", emotions are not external manifestations of internal feelings: "(a threatening) gesture does not make me think of anger, it is the anger itself' (Merleau-Ponty, 1962, p. 214).

3.1.2 Emotions as bodily acts. Emotions are bodily acts responding to the affective affordances of a given situation (Fuchs, 2017). Although they are social acts and situated interactions with others, they are always connected to body one (feeling body) (Denzin, 1984, p. 50). Such self-feelings refer to any emotion one might feel revealing her to herself through interactions and inter-subjectively constituted relations (Denzin, 1984, p. 132). Although when moved by an emotion, one might not be aware of one's body; yet being afraid, for instance, is not possible without feelings of bodily tension or trembling, a breathing of the heart or a shortness of breath. Thus, the body is a "resonance board" in which emotions reverberate James (1884) suggesting that bodily feelings are not mere "byproduct" or "add-on" distinct from emotions but the medium for affectivity (Fuchs, 2017). Importantly, however, emotions are neither pure bodily behaviours nor simple awareness of that behaviour, but require interpretation in emotional consciousness that highlights the role of self-inter-actions. According to this existential-phenomenological tradition, emotions cannot exist outside of self-feelings that arise of self-interactions where individuals direct toward themselves and out of the reflective appraisals of others (Denzin, 1984, pp. 49-53). This means that not all behaviours are emotional, but only those that are interpreted as such by the person and brought into self-inter-actions. What then is managed in an emotional experience is not an emotion but the self in the feeling of that which is being felt (Denzin, 1984). 
ITP

35,6

1788
Figure 1.

Mutual affording through gazing
3.1.3 The mutual gaze. The gaze of the other is one way through which one apprehends herself and forms perception of body and self. For Sartre, it is through the objectifying gaze of another body-subject that one can gain awareness of self (2003, p. 276). Importantly, the look is not merely about being in another's perceptual field but can do much more than this. For instance, being looked at by another can be experienced as threatening not only in a sense of bodily vulnerability but also in a more existential way of re-arranging one's world. When one feels looked at by the "other", the world changes, adopting the other's vantage point. One might feel judged, ashamed or proud. In other words, the look is not a neutral seeing but is a value-laden looking (Sartre, 2003). For Sartre, therefore, the look of the other "teaches me who I am" (Sartre, 2003, p. 298). This perspective also suggests that for Sartre, the mutual gaze is not just about convergence of two ocular globes in one's direction, but reveal the primacy of relationality: "Thus the Other has not only revealed to me what I was; he has established me in a new type of being [...] I need the Other in order to realize fully all the structures of my being" (Sartre, 2003, p. 246).

This process of inter-affectivity (Fuchs, 2017) constitutes circular interactions between body-subjects that affect and become affected by each other. The mutual gaze with another involves various possibilities for co-responding or co-affording each other. In the process of seeing and being seen, the other becomes an affective affordance and vice versa. The gaze or gesture of self and other can be seen as possibilities for different actions. In the process of seeing and being seen, one becomes body-for-the-other. At the same time, one becomes visible to herself in being aware of her physicality and seeing herself as if from a distanced perspective (Sartre, 2003). Such inter-affective affordances might be perceived as an opportunity to come closer, to walk away, to smile or disagree, and in this way, interlock in the process of co-responding becomes an emotional pattern that does not belong to any of the interlocutors who also develop different self-feelings and relations to self (Fuchs, 2017).

The circularity of mutual affording can be illustrated (Figure 1). For instance, A might feel the anger as a tension in one face or arousal in the body that translates into an expression (facial, postural and gestural) to $\mathrm{B}$, which will translate into an impression triggering corresponding or complementary bodily feelings. Thus, B not only sees the anger immediately in A's face and gestures but also senses it with her own body through her own intra-bodily resonance. However, this state does not stay like this, because the impression and bodily reaction caused in $\mathrm{B}$, in turn, becomes an expression for $\mathrm{A}$, which will immediately affect her bodily reaction and change her expression, however slightly, and so forth. This creates a circular interplay of expressions and reactions running in split seconds and constantly modifying each partner's bodily self-feeling in a process of mutual affording that becomes highly autonomous and is not controlled by the partners (Fuchs, 2017).

This perspective suggests that every social encounter is emotional, experienced bodily as something and dynamically enacted. For instance, a meeting with someone might appear boring, scary or repulsive. Importantly, we might experience such social encounters not only through actual movement sequences but through expectation or orientation to potential movements within a virtual space (Merleau-Ponty, 1962, p. 234). In this way, future situations

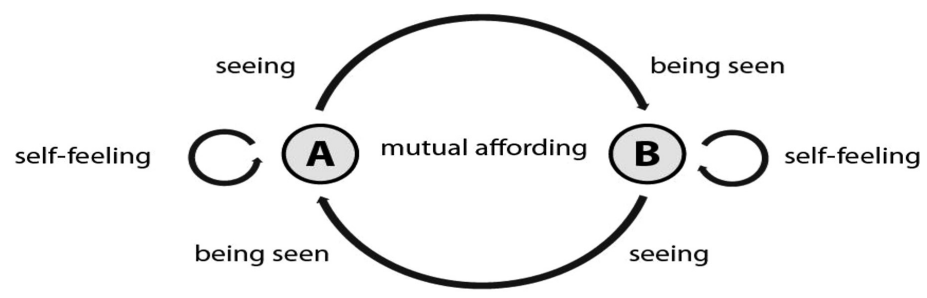


as affective affordances might appear unattractive, triggering sense of shame or social anxiety, resulting in endeavours to cultivate and control one's behaviours and appearance and also protect oneself (Dolezal, 2015).

\subsection{Body-technology relations}

The question how technology, and particularly videoconferencing tools, transform or enact such social encounters of mutual affording, and what affordances they offer for navigating them, however, remains unanswered. Don Ihde (Ihde, 2002; Rosenberg and Verbeek, 2015) gives a subtle account of our relationship with technology that is conducive to more grounded empirical analysis. This tradition of post-phenomenology draws on a relational ontology problematizing the division between subject and object or human and technology and instead viewing it as co-constitutive (Rosenberg and Verbeek, 2015). It goes beyond other phenomenological accounts (Riemer and Johnston, 2014) being interested in not only how technologies extend our sensory-motor experiences (Chughtai, 2020) but also how different "human (body)-technology-world relations" are enacted.

As such, Ihde's focus on embodiment makes his work particularly relevant to distinguishing how different relationships with technology shape inter-affective processes, affording different action possibilities for navigating social situations and encounters with others. In particular, Ihde identifies four different such relations. The first type is embodiment relation according to which technology is taken as the very medium of subjective perceptual experience of the world, transforming lived or sensory-motor experiences. This relation is illustrated with the glasses one wears that become prosthetic extension of one's sight and withdraw from attention. This relation is captured in the following form (I-technology)-world. The second type of human-technology relation is the hermeneutic relation that functions as an immediate referent to something beyond itself. Just as one might focus on a map what one is actually seeing is not the map itself but rather immediately the world or landscape it refers to. This relation can be captured in the following way I - (technology-world). The third type of human-technology relation is called "alterity" where technology is experienced as a being that is otherwise different or "technology as other". Ihde gives an example with icon or robot suggesting that in such interactions these technologies exhibit a "world of their own" or point to the possibilities of other worlds. This relationship is captured in the following way I-technology-(world). The fourth relation is not directly implicated in a conscious process of engagement on the part of the actor, and Ihde calls it background relations. It concerns relations that serve as background conditions. For instance, a traffic control system serves as a passive context for engagements or I - (technology) - world. All these human-technology relations can disclose or conceal and can magnify or reduce aspects of social encounters (Ihde, 2002; Rosenberg and Verbeek, 2015). These relations, therefore, can offer a more nuanced understanding of different affective affordances of videoconferencing technologies in expressing, amplifying or suppressing affective experiences.

\section{Research design \\ 4.1 Methodology}

This study seeks to offer insights into how videoconferencing technology constitutes and affords emotional and relational experiences of people working together in virtual context during the Covid-19 pandemic. The paper follows a phenomenological approach known as interpretive phenomenological analysis (IPA) that recognizes the central role of emotions for understanding experiences (Smith et al., 2009, p. 199). As phenomenology and hermeneutics are the philosophical base for interpretivist research (Boland, 1986), the focus here is on the meanings that people as "self-interpreting beings" (Taylor, 1985) assign to the use of videoconferencing technologies in day-to-day interactions with remote co-workers and 
ITP

35,6

1790

clients. Similar to other phenomenological studies in IS (e.g. Introna and Ilharco, 2004; Winograd and Flores, 1986), the IPA shares Heidegger's (1967) phenomenological-existential stance that meanings reside in the relationships of individuals and that emotions attune individuals to the significance of their encounters with others. This study started inductively without preconceptions and theoretical framings seeking to collect rich experiential data through semi-structured interviews and personal diaries and then continued with developing an interpretive explanation in iterative manner following the double hermeneutic approach (Boland, 1986), involving the researcher's own interpretations and the phenomenologicalexistential perspective of emotions.

\subsection{Sampling and data collection}

The study focused on 11 research participants who were employees of different multinational companies (MNCs) located in Ireland. The first three research participants were recruited through the researcher's broader social network whereas the subsequent ones were recruited through referrals. The main criterion for selecting them was their frequent videoconferencing interactions that guaranteed that they would have rich user experiences. In addition, it was expected that they have diverse interactions with both familiar and new collaborators and thus having experience of diverse social situations and encounters through videoconferencing. Prior to data collection, all interviewees had worked from home for at least six months, and the use of videoconferencing technologies has been their primary means for meeting collaborators and clients. Nine of the research participants were living with their families and children, and two of them only with their partners. All of them reported different degrees of work-related challenges in working from home, having to deal with disturbances caused by their families or partners. The IPA approach is concentrated on the depth, rather than breadth, of data collection foregrounding the importance of rich personal data and thus justifying small samples of research participants as is the case in this study (Gill, 2015).

This study relies on interviews and diaries to elicit detailed, first-person experiences from the research respondents. The interviews were conducted through videoconferencing technologies of their own preference, including Zoom, Skype and Teams, and were audio recorded and then transcribed. The questions aimed to elicit insights into their experiences using such tools. The interviews were semi-structured and continued between 1 and $1.5 \mathrm{~h}$. As it is not unusual for research participants to struggle to discursively capture and articulate their day-to-day interactions (Barley and Kunda, 2001), the use of videoconferencing tools for conducting the interviews enacted the situation they were asked about. The questions focused on their experiences and concerns (Larkin et al., 2006) aiming to gain insights into different challenges and tactics in videoconference encounters. Emphasis was put on questions about their emotional experiences and struggles and how they usually navigate and cope with them.

Five of the participants agreed to keep diaries for two months in the post-interview period and to capture additional insights of their experiences with videoconferencing technologies. They were encouraged to reflect on different social encounters, and how they have coped with them. Such personal accounts added a longitudinal dimension to the study and allowed the research participants to have more reflective engagement with the topic. After these two months, the researcher had follow-up meetings with three of the research participants to discuss their diaries. These meetings were also audio recorded and transcribed. This phase of data collection overlapped with the process of data analysis and allowed the researcher to test some of the emergent theoretical explanations and get further clarification on certain aspects of videoconferencing experiences. The researcher's own experience with videoconferencing technologies was also instrumental in steering the engagement with research participants, which was conducive to gaining richer insights. Following the phenomenological-existential tradition, the researcher has also considered his pre-conceived ideas and prejudices about 
videoconferencing experiences (Boland, 1986). The data collection ended when the richness of data offered a sense of saturation of insights and sufficient grounds for identifying analytical patterns (Walsham, 1995).

An interview guide was shared well in advance giving the possibility for the research participants to familiarize and prepare for the interview. They were also encouraged to share any concerns with the interview guide and procedures. Research participants were given the consent form to which they had to verbally agree and respond positively as it was read aloud before the interviews. During this process, interviewees were also reminded that they can withdraw without any consequences. To preserve the autonomy and privacy of research participants, their contributions were anonymized using numerical identifiers. The transcripts of both interviews and meetings were sent to the research respondents giving them sufficient time to review and offer corrections. Respondents were also given a chance to withdraw from the study during this period but were also informed that beyond this point no withdrawal of data would be possible. After this period, the numerical identifiers and actual names and contact details were deleted to prevent de-identification and re-identification of research participants.

\subsection{Data analysis}

Adhering to the guidelines of the IPA approach (Smith et al., 2009), the data analysis was both descriptive and interpretive being neither strict induction nor deduction (Denzin, 1984, p. 11). The analysis was taking place in parallel with the data collection. The researcher was listening and reading the recordings and transcripts taking notes in relation to the content, language use and context. After the first four interviews, certain themes and sub-themes started emerging. In particular, difficulties and anxieties connected to videoconferencing meetings were often reported, and this directed subsequent data collection to elaborate the interactive dynamics in situations of mutual gazing. Different emotional experiences, such as expressing, sharing or suppressing, were coded. This resonated with the phenomenological-existential tradition that emotions should be studied as lived, relational and interactional experiences (Heidegger, 1967, p. 275), directing attention to their emergent, dialectical and conflictual features (Denzin, 1984, p. 14). Focusing on the analysis on a case-by-case basis searching for patterns across individual testimonies, I started clustering the data into main themes around distinctive (emotional) experiences or situations during videoconferencing meetings, separating those that described the ways individuals coped with, reacted to or made sense of or not.

The analysis also covered the diary notes and the transcripts of the meetings discussing the diaries. They were analysed according to the themes that have emerged from the analysis of the interviews and then were compared with them looking to identify other emergent themes and additional insights. These sources of data complemented the interview transcripts but also added new more reflective insights, which helped uncover the hidden meaning of emotions often buried in everyday world (Denzin, 1984, p. 7). The aggregation of notes and the delineation of sub-themes and themes were done manually. These themes as mentioned above included different emotional experiences as well as more granular descriptions and reflections of the role of different technological features and uses for overcoming emotional situations. Following the double hermeneutic approach seeking to come up with a theoretical explanation, the researcher turned to the works of Sartre and Merleau-Ponty that helped better understand the structures, logic and interrelationships of the emotional experiences in encounters of mutual gazing (Denzin, 1984, p. 13). This process also involved identifying connections between emergent themes and understanding emotion-as-process in such virtual context. The final stage of the analysis involved systematically developing the theoretical explanation going back and forth between interview data and diary notes and the writings of Sartre (2003), Merleau-Ponty (1962) and Ihde (2002). The work of Ihde (2002) was particularly useful for structuring the presentation of findings around different body-technology relations and, respectively, refining different types of affective affordances. 
ITP

35,6

\section{Affective affordances of videoconferencing: analysis and findings}

Videoconferencing technologies enable mutual gazing, which is a matter of circular interaffective process of seeing and being seen involving mutual affording between self and other/s. The use of these technologies, however, constitute different human(body)-technology relations that not only transform in important ways how such emotional encounters are experienced but also offer different action possibilities (affordances) for navigating them: (1) embodiment relations, (2) hermeneutic relations, (3) alterity relations and (4) background relations. The analysis continues by exploring how each human(body)-technology-world or rather selftechnology-other relations in videoconferencing encounters constitute new emotional dynamics prone to risks and anxieties, but also afford new ways for coping with them.

\subsection{Embodiment relations}

Applied to videoconference encounters, this relationship suggests that one becomes immersed in the screen that withdraws from attention becoming a prosthetic extension of one's presence bringing together self and other/s. This relation can be best presented as (selfvideoconferencing technology)-other. On the one hand, it attunes us to the transformations in the processes of mutual affording in such videoconference meetings, and on the other hand, it foregrounds particular embodied ways for navigating emotional experiences by controlling how one is being seen, but also what one sees.

5.1.1 Self-view, eye contact and multiple faces: sources of new emotional dynamics. Many of the research participants shared different challenges they experienced in the process of mutual gazing facilitated through different videoconferencing tools. One common comment was the difficulty of intentionally meeting another's gaze due to the misalignment between cameral and computer screen. Some of the respondents, on the other hand, suggested that this was an advantage in meetings where intense eyeballing might take place.

Another frequent topic of discussion in the interviews and diary notes was the role of the self-view feature. Looking at oneself during calls was formative of their experiences. Some of them felt that it was a positive feature, while others discussed its disruptive dimension. Asked about why this was the case, one of the respondents argued as follows:

if you like yourself you might even feel more positive when you see your face on the screen, but if you tend to be self-critical this might be a problem for you. (R 5)

Some considered it as a positive addition to videoconferencing helping them follow their facial reactions and adjusting them appropriately:

I keep the window with my face in the upper right corner and sporadically will have a look at myself. Sometimes, I'm surprised by the emotion my face is expressing and try to adjust to something more positive [...] move my look at my interlocutor but usually it is difficult to know if he noticed the change, or the initial emotion in the first place. (R 1)

Being able to synchronize one's facial reaction with what someone is saying was also described as a form of politeness:

I followed the others' reactions and when I saw their positive or smiling faces and I tried to mimic them. (R 6)

Some of the respondents, however, also expressed scepticism about the role of the self-view feature and its role for miscommunication and confusion:

I do not know if others are handling this better than me, but I find it very difficult while talking or when just listening to follow my own expressions and this of my discussant at the same time [...] there are also delays and pauses that leave me sometimes confused and unsure of the reaction coming across. (R 4) 
In line with Sartre, mutual gazing is more than just exchanging looks, but triggers selfconsciousness or self-learning through the other. This process, however, is completely transformed by involving an additional mirror (self-view) that disrupts the circularity of expression-impression preventing the simultaneous mutual adjusting of gazes and reactions (Figure 1). Such a form of self-monitoring, whether by one or more interlocutors, introduces a degree of self-consciousness and regulation of one's self-expression that inevitably leads to different self-feelings. The struggles with the delays in syncing gazes might also explain the reports for exhaustion and difficulties to follow and understand others.

In this line of reasoning, another interesting testimony shared by a respondent was a case of a female colleague who was giving away "prolonged looks" at her self-view by making a funny grimace:

she had a mirror face very recognizable, a kind of sucked-in cheeks [ . . ] it was obvious for everyone who pays attention. I think someone told her and she felt very embarrassed. (R 10)

It was also often reported that self-view intervened with the attempts to sustain one's attention on the speaker:

I'm not sure how long time I spend focused on my face but it is a lot [...] I'm tired of looking at myself. (R8)

As this has been also sometimes sensed by others, participants engulfed in their own image would perform over-the-top reactions to create an impression of listening. For such reasons, some respondents also switched off their self-view features to later appreciate its role for selfpresentation:

It definitely bugged me and after reading about it I switched off my self-view window. Then after the meeting I realized that I had a piece of spinach between my teeth which could've been avoided had I not switched my self-view window. (R11)

Another challenging aspect of videoconferencing meetings that involve multiple participants has been monitoring the meeting dynamics and who is looking at whom:

$[\ldots]$ in a regular setting I can just monitor the movements of their bodies to get a sense of who is interested in who [...] in Zoom meetings you never know [...]. (R6)

In sum, videoconferencing technologies reconfigure the relational and emotional dynamics of social encounters creating new risks and anxieties, as well as affording new action possibilities for coping with them that will be further elaborated below.

5.1.2 Self-presentation and coping with anxiety. Most of the respondents reported premeeting grooming routines. In particular, being concerned about the way they looked, they spent time in front of the mirror fixing their appearances before meetings start. Also, depending on the importance of the meeting, some of them might change their clothes or accessories in order to convey a more professional image:

[... .] I hate to confess it but sometimes I'd put on my reading glasses just to make an impression [. . . ]

I'd try to look casual [...]. (R 10)

[...] sometimes I'd fiddle with my hair to make sure I looked as professional as possible. (R 3)

Many of them were not used to spending long hours on video calls from home, and this caused a sense of discomfort:

Seeing my makeup-less face on the screen was stressing me out. (R 2)

Constantly adjusting and monitoring one's appearance during the meetings was reported to be more common in meetings where superior or unfamiliar people were involved. In other 
ITP

35,6

1794

cases, toxic team atmosphere also resulted in significant preparation be it for regular weekly meetings. Similar to face-to-face settings, respondents felt "eye-balled" (R3) experiencing paralyzing effect, especially in one-on-one calls with their superiors.

Other interviewees shared the feeling of "every move being followed by other participants" (R 10). These insights echo Sartre's reflection of the "objectifying gaze of the other", which is experiencing as threatening, and fundamentally changing one's experience of self (Sartre, 2003, p. 246). In this regard, some interviewees observed "weird" behaviours by colleagues who might sweat or reveal anxieties by committing to additional workload pre-empting a critique of low efficiency. Thus, in such cases, we can see how unattractive future meeting can trigger anxiety and shame resulting in overcommitment as a coping strategy of avoidance (Dolezal, 2015).

5.1.3 Navigating affective affordances. In addition to different forms self-presentation that allowed respondents to control in advance how they are being seen, some of them also resorted to more radical tactics of coping with feelings of vulnerability and shame during meetings:

I came to find out that when I'm not looking at their faces, I'm more articulate and can express better. So when I speak I just either stare at my desktop background and the Zoom window is minimized or have a document covering it. (R 3)

Another participant shared a similar tactic, which also resembled an alterity relation in its attempt to withdraw from the virtual immersion to gain control in an anxious situation:

\section{[...] dimming my computer screen during presentations was particularly helpful (R1).}

These testimonies echo Sartre's and Merleau-Ponty's insights that processes of seeing and being seen are interconnected through the logic of circularity where one's expression is the other's impression and vice versa. Thus, one might navigate the emotionality of mutual affording with others not only by controlling how is being seen but also what is seeing as one needs to see how is being seen. This then becomes a way to regulate one's self-feelings by reducing one's awareness of the other, echoing Sartre's (2003) claim that looking is always value-laden and potentially judgemental.

\subsection{Hermeneutic relation}

Certain aspects of videoconference technologies also function as referent to something on the other end of the computer screen. For instance, different symbols of availability or absence, as well, as emojis are perceived not as representations per se but as the actual state of the virtual other. This relation can be expressed in the following form self - (videoconferencing technology-other). As such, it offered an emotionally safer and disembodied way of communicating that received less scrutiny.

All videoconferencing technologies have features that designate the status of self and other such as the "mute" icon or more interactive symbols, such as emojis. The merging of these videoconferencing features with the virtual other is nicely captured by a story told by one of the interviewees:

[...] we have not seen each other for ages and we started talking about our project [ . . ] there were only few people also logged in but muted and with their cameras off and we've got carried away discussing a piece of sensitive information [. . . later it transpired that one of the participants had been eavesdropping. I guess the dark screens gave us a fake sense of being alone. (R5)

In a similar vein, a number of respondents expressed frustration with meeting participants who would mute and switch off their cameras when their turn to speak nears. Showing unavailability in such a way would get them "off the hook" and would receive a more lenient treatment as if their "temporary absence was somehow justified". (R9) 
Most of the respondents also appreciated the chat function for typing questions or comments or using the "clapping" emoji as a form of support and appreciation in calls with multiple participants. These features, however, were used to fake certain attitudes:

[...] sometimes I just can't force myself to say something when some of the crappy colleagues is

being praised mostly due to self-promotional, lip service. I just then use an emoji. (R7)

Being a standardized and somewhat limited form of communication based on prefigured set of emotions, using emojis helps control one's expression and disengage from repulsive interactions. In a diary comment, one of the respondents compared some of these features with video gaming experiences where one accepts at face value the cues and reactions of the avatar as naturally linked to the remotely located players.

\subsection{Alterity relation}

In such relations, technology is experienced as other and translated to videoconferencing context it takes the form of self-videoconferencing-(other). Here the device that hosts the videoconferencing software and particularly its camera emerges as a focal entity. The focus is not on the other or on the interactive software features, but on the device that provides access to one's and other's worlds. The device became another "other" within the spatial and physical surroundings being both sources of emotional insecurity, as well as tool for selfpresentation. Indeed, many of the research participants treated their laptops or tablets as intruders in their homes because of the frequent videoconference meetings that required certain staging of their homes. In this way, decisions about the location of the device and the direction of camera had to be made in accordance with the spatial layout of the house to allow for coordination with other family members. The focus here was on the device as a referential whole (Riemer and Johnston, 2014) with the desk, walls and doors, as well as with the social routines of the household. For instance, those respondents who did not have the appropriate conditions to do it from home and struggled co-organizing their family and work lives pointing to different tactics they employed to mitigate such feelings of intrusion:

[...] sometimes I'll select my availability for a call based on whether my kids have their online sessions so that I'm sure it will be quiet around. (R 9)

It felt as if I'm letting strangers into my home, especially when I was having meetings from my bedroom. (R 11)

In the cases when respondents were having video calls with fewer people and with people who they do not know well, which for them meant that their appearances and homes would have been closely scrutinized, they would spend more time in organizing what is visible behind them and adjusting the position of their camera. In fact, most of the respondents discussed the fact that they also paid significant attention to their interlocutors' homes:

[...] sometimes you can see a partner working in the background or a child passing by or asking questions [... . the furniture or the art on the walls. (R 1)

The camera as access to one's world was also treated as a source of disruption by family members:

After the first few weeks of Zoom accidents when my partner or children will just walk into the room not realizing that I was in a conf call, anyone entering the room would first make sure to stay away from the camera. (R7)

Research participants have also pointed out that all these manipulations with the devices initially implicitly referred to access to worlds of specific others and even personalizing potential 
ITP

35,6

vulnerabilities, but over time, this connection had broken, and devices had started being seen as quasi-human pushing potential references to the world to the background (Ihde, 2002).

Similar to embodied relations, when participants employed different tactics of navigating social affordances, alterity relations were conducive to such tactics for reducing visibility and protecting from the gaze of others. For instance, positioning oneself further away from the camera was a way to cope with stressful meetings. Other respondents would select the appropriate position of their devices in relation to the nearest window so that the daylight makes their appearance somewhat blurry. These tactics were similar to those of embodiment relations, but were addressing potential threatening experiences caused by the "objectifying gaze of the other" (Sartre, 2003, p. 246) through the physical and spatial positioning to the device hosting the videoconferencing application.

While most tactics indeed sought to deal with mitigating the objectifying gaze of the other (Sartre, 2003), there were also other situational circumstances that triggered a sense of frustration. One of the interviewees, for instance, expressed his frustration with a colleague who would come up with "lame" excuses for slow broadband connection and switch off his video despite being clear that he is just disguising his location and spending "time somewhere in the beach, pretending he was working from home". (R3)

\subsection{Background relations}

Don Ihde describes background relations as those that "blackbox" the technology and makes it retrieve to the background. In videoconferencing context, these insights do not translate well, but we can interpret the features of virtual background and filters as aspects of this relation. They similarly serve as a passive context for engagement withdrawing from immediate attention and creating a feeling of immersive reality in which self and other exist: self - (videoconferencing) - other.

Many of the respondents discussed the virtual background and filters that they often used for aesthetic reasons. Although many of them felt that choosing a "bright" or "funny" background improves the meeting atmosphere and offers a safe topic for discussion, some of them felt that such "colourful backgrounds" were not professional. Some of the respondents would also change the virtual background to avoid matching the colours of their clothes in important meetings.

The key reason, however, for using the backgrounds or filters has been for its "protective" role as a "veil" (R10) that makes invisible their physical surroundings. One of the respondents also spoke about the feeling of being in a computer game re-enforcing the sense of a "surreal" experiences. (R2)

While many of the respondents reported for having experimented with blurring their background or using images to virtualize it that offered a "controlled and safe physical surrounding" (R 1), some of them over time stopped using such backgrounds:

[...] it is as a basic reciprocity of hospitality that might make you a bit vulnerable but not too different from any other ordinary encounter. (R 5)

Such a form of self-disclosing was usually done in friendly meetings echoing the understanding that emotions, such as shame or anxiety, can be triggered by anticipated future situations resulting in premature attempts to protect oneself (Dolezal, 2015). The testimonies for opting in or out of having a background as a safety veil according to the particular meeting illuminate the claim that affective affordances as action possibilities both conceal or disclose, reduce or magnify (Ihde, 2002; Rosenberg and Verbeek, 2015).

\section{Discussion}

The aim of this study has been to contribute to the extant literature on emotions in virtual work context (Panteli et al., 2021). By drawing on an interpretive phenomenological study of videoconference meetings, this paper has offered insights into the experiences of virtual 
collaboration through videoconferencing technologies. Sensitized by a phenomenologicalexistential perspective on emotions, the findings reveal the anatomy and dynamics of emotions and particularly the ways they emerge and are dealt with in situations of mutual gazing. The study employs the notion of affective affordance following the understanding that technology is constitutive of emotional experiences in virtual settings (Fineman et al., 2007; Walther, 1995), showing how they orient us to certain action possibilities for navigating anxious encounters. This notion further enables a more nuanced and granular understanding of human (body)technology relations that expand our understanding of the relationship between technology, body and emotions.

The phenomenological-existential perspective on emotions foregrounds their relational and interactive origin showing that emotions are fluid, lived and dynamic experiences. This perspective on emotions highlights the circularity of seeing and being seen, or "body one" and "body two" contribute to recent studies striving to better understand the embodied and interactive aspects of virtual collaboration (e.g. Schultze and Brooks, 2019; Stewart and Schultze, 2019; Vachhani and Pullen, 2019). This study also adds rich empirical insights to research on videoconferencing technologies (Hacker et al., 2020; Karl et al., 2021), with particular emphasis on the role of emotions in situations of mutual gazing. In contrast to interpretations that feelings of anxiety and exhaustion in virtual meetings are evidence of techno-stress (Ayyagari et al., 2011; Tarafdar et al., 2010), technology here is viewed not as an end point and source of stress, but as co-constitutive of emotional relational experiences.

This study also re-enforces and furthers the understanding that emotions in virtual context should be studied in their own right (Fineman et al., 2007; Walther, 1995) by pointing to different socio-technical practices and tactics that diverge from face-to-face interactions. These include acts of adjusting body postures and eye contact in relation to the camera with a view to calibrating the distance and angle to it. In addition, the findings foreground engagements through emojis, such as clapping or favouriting, and tinkering with different videoconferencing features, such as different views (gallery or active speaker), background and self-view window, as well as adjusting their size and location on the screen. While some of these features and gestures have been already reported by studies exploring videoconferencing technologies (e.g. Geenen, 2017; Karl et al., 2021; Regenbrecht and Langlotz, 2015), this paper provides different interpretations of their significance through the lens of the circularity of seeing and being seen as a structuring process of emotional experience and expressions. For instance, the "self-view" window as a feature of videoconference experiences has received little critical attention, but this study highlights significant implications for the ways it transforms mutual gazing. In particular, the findings show that it introduces a disruption in the way one develops a sense of self and other. Supplanting the role of the "other" as a "mirror" for self, that is in the centre of spontaneous, embodied communication and thereby of feelings of empathy and trust, carries a risk of more substantial transformation of the human condition. Having another "mirror" (selfview) in addition to that of the face of the "other" not only creates difficulties of monitoring and adjusting divergent appearances that might explain reports of interactive exhaustion but also threatens to transform the inter-corporeal origin of sociality and may promote distorted identities.

The findings also point to another central facet of the transformative role of videoconferencing technologies in situations of mutual gazing concerning the fact that what and who one sees cannot be seen through the screen by the "other". Such a split in the mutual gaze allows the interlocutors to manipulate what and who they see without bearing the consequences that, for instance, a continuous look at someone might have in face-to-face meetings. At the same time, without being able to ascertain the direction and duration of the gazes of others, interlocutors tend to experience feelings of being constantly looked at or eyeballed, which engender feelings of anxiety. It can be argued that the break in the
Affective
affordances

1797 
ITP

35,6

circularity of seeing and being seen in virtual context can account for the heightened degrees of anxiety and self-consciousness in virtual meetings and, respectively, explain the emergence of new affective affordances for regulating self-feelings and protecting identities. Moreover, the reports of Zoom fatigue (Bailenson, 2021) can be linked to these findings suggesting that "self-view" distortion, delays and split of the process of mutual gazing also result in excessive efforts and needs for skills to navigate and regulate such new emotional experiences and expressions in order to sustain the process of mutual affording crucial for conducting purposeful activities.

Importantly, this study offers insights into different affective affordances of videoconferencing technologies that illuminate different tactics for navigating and mitigating feelings of anxiety. The notion of affective affordance enriches the understanding that technology is constitutive of emotional experiences and expressions illuminating the strategic behaviours of interlocutors who are always already emotionally oriented and act in accordance to the situation in which they find themselves (Ciborra, 2002).

The findings of this paper, however, also show that a focus on emotions not only offers richer interpretations of virtual collaboration processes (e.g. Aarrestad et al., 2015) but also illuminates collaborative practices as action possibilities that can remain hidden in day-to-day activities or be glossed over by more traditional interpretations of emotions (Denzin, 1984). In particular, the phenomenological-existential perspective on emotions sensitizes us to different tactics for navigating emotional experiences either disclosing or concealing vulnerabilities. These include staging and coordinating family and household activities, excessive pre-meeting grooming, spatial or physical positioning aimed at improving self-presentation and preventing expectations for shameful and anxiety-provoking feelings. In addition, practices of dimming the screen or covering the videoconference application window with other windows become significant as emotional tactics based on the understanding of the inseparability of seeing and being seen and that seeing equates affecting.

In contrast with studies that generalize the human-technology relation as entanglement (Beane and Orlikowski, 2015; Introna and Hayes, 2011), this study offers richer interpretations and discriminates between different entanglements in accordance to the specific connection with the body. The findings here, thus, also expand our understanding of the materiality of videoconferencing technologies revealing the interconnectedness with the body and confirming the inseparability between virtual and physical (Introna, 2007; Schultze, 2014). For instance, the findings show that physical and spatial positioning of the bodies, in terms of distance, angle and even daylight, shape virtual behaviours and images and vice versa, blurring the difference between virtual and physical expressions.

These findings also hold important practical implications. For instance, the design of videoconferencing technologies appears to be premised on more rational perspectives for understanding collaboration ignoring the importance of the emotional dynamics uncovered here. Considering the insights of this study, designers of videoconferencing technologies might incorporate functionalities that afford ways for mitigating feelings of anxiety and facilitating the process of mutual affording.

This study is not without limitations. One such limitation is the focus on individual experiences in different organizations, which offers scarce insights into the specific organizational context that would otherwise deepen our understanding of the sources of anxiety and the choice of tactics for coping with them. Another limitation of this work is the exclusive focus on videoconferencing technologies that shape only partly virtual relationships, and in this way, the complementary role of other technologies and how they co-constitute the navigation of emotional dynamics remain to be further explored. In addition, future research can also elaborate the findings of this study by exploring how users select certain affective affordances and under what circumstances these preferences emerge. 


\section{Conclusion}

The Covid-19 pandemic has stimulated the widespread use of videoconferencing technologies across the globe. They have been used for connecting physically separated family members and co-workers and have also given rise to new forms of expressing solidarity and compassion. New virtual socialities have also thrived through them. Despite the growing popularity of these technologies and their role in facilitating relational and emotional encounters, little do we know about them beyond their functional uses to support purposeful activities.

This paper made strides in this direction uncovering the constitutive role of videoconferencing technologies in virtual encounters of mutual gazing. More specifically, this study showed that such virtual meetings are inherently inter-affective and foregrounded how different affective affordances offer action possibilities to conceal or disclose emotional experiences. Furthermore, the paper offers nuanced insights that can advance current research discourse on the relationships between technology, human body and emotions.

\section{Notes}

1. https://www.pololifestyles.com/single-post/host-a-smashing-virtual-happy-hour-getting-smashedis-optional

2. https://qz.com/work/1849236/how-to-hide-yourself-on-zoom-and-why-you-should/

\section{References}

Aarrestad, M., Brøndbo, M.T. and Carlsen, A. (2015), "When stakes are high and guards are low: highquality connections in knowledge creation”, Knowledge and Process Management, Vol. 22 No. 2, pp. 88-98.

Ayyagari, R., Grover, V. and Purvis, R. (2011), "Technostress: technological antecedents and implications", MIS Quarterly, Vol. 35 No. 4, pp. 831-858.

Bailenson, J. (2021), "Nonverbal overload: a theoretical argument for the causes of zoom fatigue", Technology, Mind, and Behavior, Vol. 2 No. 1, doi: 10.1037/tmb0000030.

Bala, H. and Bhagwatwar, A. (2018), "Employee dispositions to job and organization as antecedents and consequences of information systems use", Information Systems Journal, Vol. 28 No. 4, pp. 650-683.

Baralou, E. and Tsoukas, H. (2015), "How is new organizational knowledge created in a virtual context? An ethnographic study", Organization Studies, Vol. 36 No. 5, pp. 593-620.

Barley, S. and Kunda, G. (2001), "Bringing work back in”, Organisation Science, Vol. 12 No. 1, pp. 76-95.

Bateman, P.J., Gray, P.H. and Butler, B.S. (2011), "The Impact of community commitment on participation in online communities", Information Systems Research, Vol. 22 No. 4, pp. 685-891, doi: 10.1287/isre.1090.0265.

Beane, M. and Orlikowski, W.J. (2015), "What difference does a robot make? The material enactment of distributed coordination”, Organization Science, Vol. 26 No. 6, pp. 1553-1573, doi: 10.1287/ orsc.2015.1004.

Boland, R.J. (1986), "Phenomenology: a preferred approach to research on information systems", Trends in Information Systems, NLD: North-Holland, pp. 341-349.

Buchanan, T. and Whitty, M.T. (2013), "The online dating romance scam: causes and consequences of victimhood", Psychology, Crime and Law, Vol. 20 No. 3, pp. 261-283.

Carlson, J.R. and Zmud, R.W. (1999), "Channel expansion theory and the experiental nature of media richness perceptions", Academy of Management Journal, Vol. 42 No. 2, pp. 153-170.

Chughtai, H. (2020), "Taking the human body seriously", European Journal of Information Systems, Vol. 0 No. 0, pp. 1-17. 
ITP

35,6

1800

Ciborra, C. (2002), "Kairos (and affectio)", The Labyrinths of Informaiton: Challenging the Wisdom of Systems, Oxford University Press, Oxford.

Daft, R.L. and Lengel, R.H. (1986), "Organizational information requirements, media richness theory and structural design”, Management Science, Vol. 32 No. 5, pp. 554-571.

Dennis, A.R., Rennecker, J.A. and Hansen, S. (2010), "Invisible whispering: restructuring collaborative decision making with instant messaging", Decision Sciences, Vol. 41, pp. 845-886.

Denzin, N. (1984), On Understanding Emotion, Jossey-Bass, San Francisco,

Diprose, R. (2002), "Corporeal generosity : on giving with Nietzsche, Merleau-Ponty, and Levinas", SUNY Series in Gender Theory, State University of New York Press, Albany.

Dolezal, L. (2015), The Body and Shame Phenomenology, Feminism, and the Socially Shaped Body, Lexington Books, London.

Dreyfus, H.L. (2008), On the Internet (Thinking in Action), Routledge, London.

Dubé, L. and Robey, D. (2009), "Surviving the paradoxes of virtual teamwork", Information Systems Journal, Vol. 19 No. 1, pp. 3-30.

Fineman, S., Maitlis, S. and Panteli, N. (2007), "Themed articles: virtuality and emotion: introduction", Human Relations, Vol. 60 No. 4, pp. 555-560.

Fuchs, T. (2017), "Intercorporeality and interaffectivity", in Meyer, C., Streeck, J. and Jordan, S. (Eds), Intercorporeality: Emerging Socialities in Interaction, Oxford Scholarship Online, Oxford.

Fuchs, T. and de Jaegher, H. (2009), "Enactive intersubjectivity: participatory sense-making and mutual incorporation", Phenomenology and the Cognitive Sciences, Vol. 8 No. 4, pp. 465-486.

Geenen, J. (2017), "Show and (sometimes) tell: identity construction and the affordances of videoconferencing", Multimodal Communication, Vol. 6 No. 1, pp. 1-18.

Gibson, J. (1986), The Ecological Approach to Visual Perception, Lawrence Erlbaum Associates, Hillsdale, NJ.

Gill, M.J. (2015), "A phenomenology of feeling: examining the experience of emotion in organizations", New Ways of Studying Emotions in Organizations, Research on Emotion in Organizations, Emerald Group Publishing, Vol. 11, pp. 29-50.

Gilmore, S. and Warren, S. (2007), "Emotion Online: Experiences of Teaching in a Virtual Learning Environment”, Human Relations, Vol. 60, pp. 581-607.

Hacker, J., vom Brocke, J., Handali, J., Otto, M. and Schneider, J. (2020), "Virtually in this together how web-conferencing systems enabled a new virtual togetherness during the COVID-19 crisis", European Journal of Information Systems, Taylor \& Francis, Vol. 29 No. 5, pp. 563-584.

Hafermalz, E. and Riemer, K. (2020), "Interpersonal connectivity work: being there with and for geographically distant others", Organization Studies, Vol. 41 No. 12, pp. 1627-1648.

Heidegger, M. (1967), Being and Time, Blackwell, Oxford.

Heidegger, M. and Boss, M. (2001), Zollikon Seminars: Protocols, Conversations, Letters, Northwestern University Press, Evanston, Illinois.

Hinds, P. and Kiesler, S. (2002), "Distributed work", in Hinds, P.J. and Kiesler, S. (Eds), Distributed Work, The MIT Press, Vol. 47.

Ihde, D. (2002), Bodies in Technology, University of MinnesotaPress, Minneapolis.

Introna, L. (2007), "Towards a post-human intra-actional account of socio-technical agency (and morality)”, The Moral Status of Technical Artefacts, Springer, Dordrecht, pp. 31-53.

Introna, L.D. and Hayes, N. (2011), "On sociomaterial imbrications: what plagiarism detection systems reveal and why it matters", Information and Organization, Elsevier, Vol. 21 No. 2, pp. 107-122.

Introna, L.D. and Ilharco, F.M. (2004), "The ontological screening of contemporary life: a phenomenological analysis of screens", European Journal of Information Systems, Vol. 13 No. 3, pp. 221-234.

James, W. (1884), “What is an emotion?”, Mind, No. 9, pp. 188-205. 
Karl, K.A., Peluchette, J.V. and Aghakhani, N. (2021), "Virtual work meetings during the COVID-19 pandemic: the good, bad, and ugly", Small Group Research, pp. 1-23, 10464964211015286.

Larkin, M., Watts, S. and Clifton, E. (2006), "Giving voice and making sense in interpretative phenomenological analysis", Qualitative Research in Psychology, Vol. 3 No. 2, pp. 102-120.

Leonardi, P.M. and Vaast, E. (2017), "Social media and their affordances for organizing: a review and agenda for research", Academy of Management Annals, Vol. 11, pp. 150-168.

Maier, C., Laumer, S., Weinert, C. and Weitzel, T. (2015), "The effects of technostress and switching stress on discontinued use of social networking services: a study of Facebook use", Information Systems Journal, Vol. 25 No. 3, pp. 275-308.

Malhotra, A. and Majchrzak, A. (2014), "Enhancing performance of geographically distributed teams through targeted use of information and communication technologies", Human Relations, Vol. 67 No. 4, pp. 389-411.

Markus, M.L. (1994), "Electronic mail as the medium of managerial choice", Organization Science, Vol. 5 No. 4, pp. 502-527.

Maznevski, M.L. and Chudoba, K.M. (2000), "Bridging space over time: global virtual team dynamics and effectiveness", Organization Science, Vol. 11 No. 5, pp. 473-492.

McGrath, K. (2006), "Affection not affliction: the role of emotions in information systems and organizational change", Information and Organization, Vol. 16 No. 4, pp. 277-303.

Merleau-Ponty, M. (1962), Phenomenology of Perception, Routledge, London.

Merleau-Ponty, M. (1968), The Visible and the Invisible, Northwestern University Press, Evanston.

Ngwenyama, O. and Lee, A. (1997), "Communication richness in electronic mail: critical social theory and the contextuality of meaning", MIS Quarterly, Vol. 21 No. 2, pp. 145-167.

Panteli, N., Giaver, F. and Engesmo, J. (2021), "Call for papers: special issue on emotions in the digitalised workplace", Information Technology and People.

Ramesh, V. and Dennis, A. (2002), "The object oriented team: lessons for virtual teams from global software development", System Sciences, Vol. 00 No. c, pp. 1-10.

Regenbrecht, H. and Langlotz, T. (2015), "Mutual gaze support in videoconferencing reviewed", Communications of the Association for Information Systems, Vol. 37, pp. 965-989.

Ren, Y., Kraut, R. and Kiesler, S. (2007), "Applying common identity and bond theory to design of online communities”, Organization Studies, Sage Publications, Sage, London, Vol. 28 No. 3, pp. $377-408$.

Riemer, K. and Johnston, R.B. (2014), "Rethinking the place of the artefact in IS using Heidegger's analysis of equipment", European Journal of Information Systems, Vol. 23 No. 3, pp. 273-288.

Robey, D., Schwaig, K.S. and Jin, L. (2003), "Intertwining material and virtual work”, Information and Organization, Vol. 13 No. 2, pp. 111-129.

Rosenberg, R. and Verbeek, P. (2015), Postphenomenological Investigations: Essays on HumanTechnology Relations, Lexington Books, London.

Sartre, J. (2003), Being and Nothingness: an Essay on Phenomenological Ontology, Routledge, London.

Schinoff, B.S., Ashforth, B. and Corley, K. (2019), "Virtually (In)Separable: the centrality of relational cadence in the formation of virtual multiplex relationships", Academy of Management Journal, Vol. 63 No. 5, pp. 1395-1424.

Schultze, U. (2014), "Performing embodied identity in virtual worlds", European Journal of Information Systems, Vol. 23, pp. 84-95.

Schultze, U. and Brooks, J.A.M. (2019), "An interactional view of social presence: making the virtual other real”, Information Systems Journal, Vol. 29, pp. 707-737.

Schultze, U. and Orlikowski, W.J. (2001), "Metaphors of virtuality: shaping an emergent reality", Information and Organization, Vol. 11, pp. 45-77. 
ITP

35,6

1802

Smith, J., Flowers, P. and Larkin, M. (2009), Interpretative Phenomenological Analysis: Theory, Method and Research, Sage, London.

Springgay, S. (2005), "Thinking through bodies: bodied encounters and the process of meaning making in an E-mail generated art project", Studies in Art Education, Vol. 47 No. 1, pp. 34-50.

Stein, M.-K., Newell, S., Wagner, E.L. and Galliers, R.D. (2015), "Coping with information technology”, MIS Quarterly, Vol. 39 No. 2, pp. 367-392.

Stewart, M. and Schultze, U. (2019), "Producing solidarity in social media activism: the case of my stealthy freedom", Information and Organization, Vol. 29 No. 3.

Strong, D., Volkoff, O., Johnson, S., Pelletier, L., Tulu, B., BAr-On, I., Trudel, J. and Garber, L. (2014), “A theory of organization-EHR affordance actualization", Journal of the Association of Information Systems, Vol. 15 No. 2, pp. 53-85.

Suchman, L. (2007), Human-machine Reconfigurations: Plans and Situated Actions, Cambridge University Press, Cambridge, UK.

Tarafdar, M., Tu, Q. and Ragu-Nathan, T.S. (2010), "Impact of technostress on end-user satisfaction and performance", Journal of Management Information Systems, Routledge, Vol. 27 No. 3, pp. 303-334.

Taylor, C. (1985), Human Agency and Language, Cambridge University Press, Cambridge, UK.

Thompson, M. (2012), "People, practice, and technology: restoring giddens' broader philosophy to the study of information systems", Information and Organization, Vol. 22 No. 3, pp. 188-207.

Tsoukas, H. (2009), "A dialogical approach to the creation of new knowledge in organizations", Organization Science, Vol. 20 No. 6, pp. 941-957.

Vaast, E. (2007), "Playing with masks: fragmentation and continuity in the presentation of self in an occupational online forum", Information Technology and People, Vol. 20 No. 4, pp. 334-351.

Vachhani, S.J. and Pullen, A. (2019), "Ethics, politics and feminist organizing: writing feminist infrapolitics and affective solidarity into everyday sexism”, Human Relations, Vol. 72 No. 1, pp. 23-47.

Vidolov, S., Kelly, S. and Noonan, C. (2020), "Project management as skilful performance: animating and enchanting collaborative work in distributed projects", ICIS 2020 Proceedings.

Waizenegger, L., McKenna, B., Cai, W. and Bendz, T. (2020), "An affordance perspective of team collaboration and enforced working from home during COVID-19", European Journal of Information Systems, Vol. 29 No. 4, pp. 429-442.

Walsham, G. (1995), "The emergence of interpretivism in IS research", Information Systems Research, Vol. 6 No. 4, pp. 376-394.

Walther, J.B. (1995), "Relational aspects of computer-mediated communication: experimental observations over time", Organization Science, Vol. 6 No. 2, pp. 186-203.

Walther, J., Van Der Heide, B., Ramirez, A., Burgoon, J.K. and Peña, J. (2015), "Interpersonal and hyperpersonal dimensions of computer-mediated communication”, in Sundar, S.S. (Ed.), The Handbook of the Psychology of Communication Technology, Wiley Blackwell, pp. 3-22.

Warren, T. (2020), Zoom Grows to 300 Million Meeting Participants Despite Security Backlash, The Verge, available at: https:/www.theverge.com/2020/4/23/21232401/zoom-300-million-usersgrowth-coronavirus-pandemic-security-privacy-concerns-response.

Wastell, D.G. (1996), "The fetish of technique: methodology as a social defence", Information Systems Journal, Vol. 6 No. 1, pp. 25-40.

Weiss, G. (2008), “Ambiguity”, in Diprose, R. (Ed.), Merleau-Ponty: Key Concepts, Acumen Publishing, pp. 132-141.

Winograd, T. and Flores, F. (1986), Understanding Computers and Cognition: A New Foundation for Design, Adison-Wesley Publishing Company, CA. 
Zaveri, P. (2020), Microsoft Teams Now Has 75 Million Daily Active Users, Adding 31 Million in Just over a Month, Business Insider, available at: https://www.businessinsider.com/microsoft-teamshits-75-million-daily-active-users-2020-4.

Affective affordances

Corresponding author

Simeon Vidolov can be contacted at: simeon.vidolov1@ucd.ie

For instructions on how to order reprints of this article, please visit our website: www.emeraldgrouppublishing.com/licensing/reprints.htm Or contact us for further details: permissions@emeraldinsight.com 